\title{
Innovative Development Path of State-owned Economy -- Evidence Based on The Impact of COVID-19 on The Development of Chinese State-owned Industrial Enterprises and Their Post- epidemic Recovery from Financial Perspective
}

\author{
Qinyuan $\mathrm{Li}^{1, *}$, Shijie Tan ${ }^{2}$ \\ ${ }^{1}$ Accounting, School of Accounting(MPAcc education center), Shanxi University of Finance and Economics, Taiyuan, Shanxi, China \\ ${ }^{2}$ Insurance, School of Finance, Shanxi University of Finance and Economics, Taiyuan, Shanxi, China
}

\begin{abstract}
Since the spread of the COVID-19, State-owned industrial enterprise have faced many problems such as industrial and supply chain breaks, shutdowns and insufficient production capacity, which are common in the state-owned economy. Financial indicators can often better dig out the economic problems behind them, so we screened 20 relevant composite financial indicators including asset yield, return stability, debt solvency, cumulative profitability, liquidity, capitalization, and scale. After correlation analysis, a significant "Operating income growth rate" indicator was obtained and the ARIMA model was used to predict and compared the results with the actual value. During the first and second outbreaks of the COVID-19, its influence path is to affect the supply and demand of the production, then affect the financial status. The negative impact gradually weakened after March 2020. During the second outbreak in July 2020, the Stateowned industrial enterprises were the most negatively affected then gradually recovered. After analysis, we found that the innovation of Chinese state-owned economy, due to its special status in the economy, emergency management and its role in the supply chain and industrial chain should be emphasized. The innovation of the state-owned economy will play an important role in promoting economic innovation.
\end{abstract}

\section{Introduction}

In 2020, the concept of enhancing the innovation capability of Chinese state-owned economy was formally proposed for the first time, which has very important guiding significance for the future reform and development of China's state-owned economy and stateowned enterprises, as well as the realization of highquality development of the national economy and the construction of a modern economic system. This includes advancing the optimization and structural adjustment of the state-owned economy, developing a mixed-ownership economy, enhancing the competitiveness, innovation, control, influence, and anti-risk capabilities of the stateowned economy, strengthening and expanding the stateowned economy, and realizing the innovative development of the state-owned economy.

The high-quality development of state-owned industrial enterprises is not only an important part of consolidating the dominant position of public ownership and realizing the common development of multiple ownership economies, but also an important guarantee for higher-level and larger-scale adherence and improvement of the basic socialist economic system ${ }^{[1]}$. As an important part of manufacturing enterprises, state-owned industrial enterprises are also an important material and political foundation for socialism with Chinese characteristics. The high-quality development of state-owned industrial enterprises plays an important role in the progress of Chinese society and the upgrading of manufacturing industry. It is necessary to rationally understand the reality basis and problem gaps, combined with the situation of the new era, and actively explore the development of stateowned power in the manufacturing enterprises in the new era, and realize the direction of high-quality development of state-owned industrial enterprises at the individual level and the overall level.

Since the outbreak of COVID-19 in January 2020, my country's total GDP in the first quarter of 2020 has fallen by $6.8 \%$ year-on-year. People's life safety and corporate financial conditions have been greatly threatened. For industrial enterprises, they generally face industrial chains and There are many production and capital source issues such as supply chain breaks, shutdowns and insufficient production capacity. State-owned industrial enterprises, as an important part of industrial enterprises, played an important role in maintaining the development of the industry, resisting the risk of shutdown and production, and restoring the vitality of the industry in this epidemic. Therefore, this article conducts in-depth research on the development impact of state-owned industrial enterprises during the COVID-19, and uses the production data of

*Corresponding author: 1105782778@qq.com 
industrial enterprises to conduct in-depth research to determine the development impact of state-owned industrial enterprises in the COVID-19 and target the future development of state-owned industrial enterprises. The path gives relevant suggestions, as well as response methods and emergency plans in the event of similar major public health incidents. According to the time dimension, this article takes the COVID-19 as an important occurrence node, taking state-owned industrial enterprises as an example, and characterizes the path of innovative development of the state-owned economy.

\section{Literature review}

\subsection{Research on the impact of COVID-19 on the economy and society}

After the outbreak of the COVID-19, relevant research on the impact of the COVID-19 on the economy and society has gradually expanded theoretically and empirically. Existing studies have emphasized the degree and content of the impact of the development of the epidemic on society from a socio-economic perspective. Rendon et al. ${ }^{72}$ combined the characteristics of different evolutionary methods to block the prevention and control of the inducing conditions of crisis events (Chen C. and Zhao D., $2021)^{4}$, and used the Dagum Gini coefficient method to study the impact of the epidemic on China's regional economy (Liu S., 2021) ${ }^{2}$, studied how to make strategic adjustments and alleviate the negative impact of the COVID-19 on economic and social development, and realize the measures and methods to restore the internal vitality of the Chinese economy and realize the conversion of kinetic energy (Yu Y. et al., 2020) $)^{5}$. The development of globalization in the economic context has also become the focus of research, as well as the economic recovery and the impact of related policies on the socio-economic effects after the COVID-19 (Du J. and Zhao W., 2020) ${ }^{6}$ Explained and theoretically explained and continued the post-epidemic era and high-quality economic and social development (Fan H., 2020) ${ }^{7}$.

\subsection{Research on the impact of industrial sectors}

In the existing research, for the industrial industry, there is a research on the relevant influence mechanism of the development of the industry and the stable operation of the industry. Research on the measurement of China's industrial green total factor productivity and related influencing factors illustrates the relevant mechanisms and mechanisms in the operation of the entire industry (Liu S. et al., 2020) ${ }^{10}$. And in the research, the economic efficiency measurement and related influencing factors were explored for the geographical difference (Fang D., $2020)^{8}$, and the methods and models under the advancement of industrial technology were explored (Yang Z., 2017) ${ }^{11}$. And from the environmental perspective (Gu Z., 2014) ${ }^{14}$, energy supply (Luo M., 2020) ${ }^{15}$, and economic environment (Yang Z., 2017) ${ }^{11}$, it explained and empirically analyzed the impact of the industrial sector.
In the research methods of influencing factors used, the existing research mainly uses the DEA-BCC model, the DEA-Malmquist index method (Fang D., 2020) ${ }^{8}$, and the PCA analysis method (Wang Y. et al., 2013) ${ }^{13}$. And from the perspective of supply chain (Ali et al., 2021) ${ }^{9}$ and circular economy (Lieder et al., 2016) ${ }^{12}$, the impact of industry is analyzed.

\subsection{Literature review}

At present, most of the existing research on the economic and social impact of COVID-19 has focused on the macrolevel research on society or certain regions. There are relatively few studies on the impact of specific industries. At the same time, when studying the impact measurement and influencing factors of the industrial sector, the models and methods are relatively single, and there is a lack of analysis from the perspective of time series. We also found that the research perspective on the impact of industrial enterprises is not from a financial perspective. From a financial perspective, this article uses the ARIMA model to determine the impact of the COVID-19 and the degree of recovery after the epidemic to calculate and analyze the development and recovery of state-owned industrial enterprises. It has innovative value and practical reference significance.

\section{Data sources}

\subsection{Data sources}

The survey data used in this article is the official statistical survey data of the National Bureau of Statistics, and the starting standard of the industrial enterprises above designated size participating in the survey is 20 million yuan in main business income and 20 million yuan in main business cost.

The financial data used in this article is derived from the relevant data of state-owned industrial enterprises in the database. The data is the cumulative amount of each month and the period is from January 2015 to February 2021, including January 2015, January 2016, January 2017, January 2018, January 2019, January 2020 and January 2021 don't need to report.

\subsection{Data Preprocessing}

During the data preprocessing, We found that due to certain differences in the statistical reporting system, the financial indicators of enterprises in different years are not completely the same.

First of all, the indicators and secondary indicators that differ from year to year are eliminated, and the same important indicators are retained. In the end, this article retains 27 indicators for observation and research. Among them, the next item "Accounts Receivable", which is the sum of current assets in 2018 and 2020, is "Notes Receivable and Accounts Receivable" in 2019. Observe that the data has not changed much, so the "notes and 
accounts receivable" in 2019 is equated with "accounts receivable".

In 2018, there was an indicator of "main business income and cost", and in 2019 and 2020, it was changed to "business income, cost". However, the data difference is not big, so the main business income and cost will replace the operating business income and cost.

\subsection{Statistical description}

First, observe in some selected indicators. Before the outbreak of the epidemic, the growth rate of assets and liabilities fluctuates greatly, and their values alternately lead. After February 2020, the growth rates of assets and liabilities are very close with little volatility, and reached their respective maximum values of $12 \%$ in August 2020. In contrast, the growth rate of operating income and operating costs always showed the same trend regardless of whether the epidemic occurred or not. The values of the two were greatly affected by the epidemic. During the outbreak of the COVID-19, there was a greater impact. The volatility caused the value to be less than 0 , but starting from March 2020, the growth rate of operating income and operating cost gradually increased, especially after entering 2021, the growth rate of both came to about $22 \%$, which is the last two years data.

At the same time, this article finds that the growth rates of operating profit and total turnover for the entire year of 2019 are both negative and have relatively small fluctuations. In contrast, they are more affected by the COVID-19. From February 2020 to December 2020, the growth rate of operating profit and total profit is always less than 0 , and it reached the lowest level in history in August: $-67.5 \%$ and $-60.6 \%$. However, the growth rate of operating profit and total turnover has ushered in a new explosive growth after entering 2021, and the growth rates have reached historical highs: $109.8 \%$ and $110.3 \%$. Behind this is the impact of economic driving forces. The results of economic innovation can be reflected by changes and fluctuations in economic data.So related research will be helpful to economic innovation.

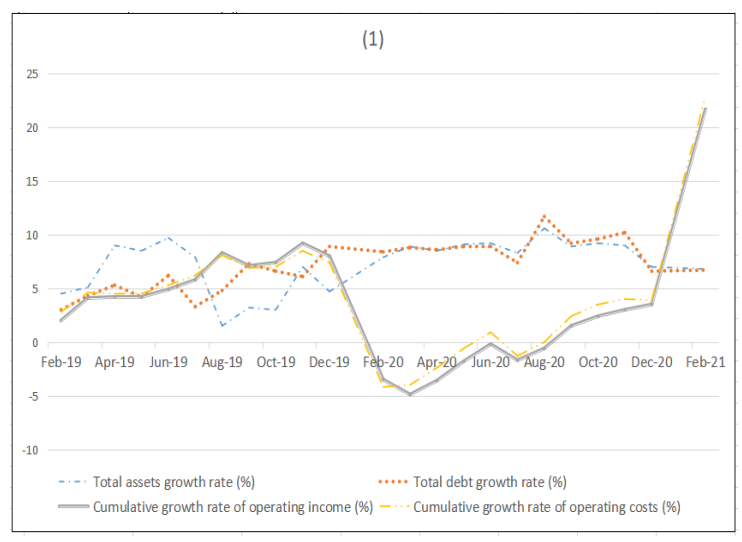

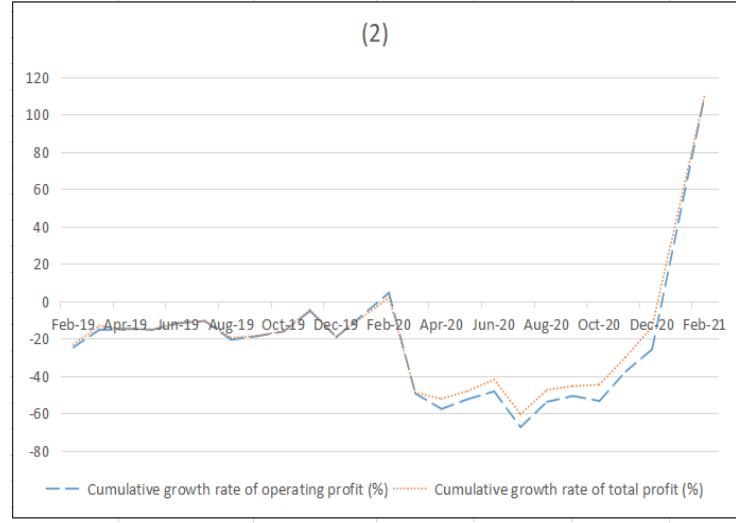

Figure 1. The growth rate of some indicators (1), (2)

\section{Empirical analysis}

\subsection{Theoretical framework}

The theoretical framework for modeling in this paper is based on the financial indicator data from the National Bureau of Statistics, forming 20 composite financial indicator data. By screening specific composite financial indicator data, the development impact of state-owned industrial enterprises affected by the COVID-19 is studied.

In the selection of financial indicators, the research ideas in the corporate financial distress model are mainly used for reference. There are multiple financial indicator types in the comprehensive financial indicator information category, of which the ZETA credit risk model are mainly used, including seven indicators: Return on assets, income stability indicators, debt solvency indicators, cumulative profitability indicators, liquidity indicators, capitalization degree indicators, and scale indicators.

The time series data of the financial indicators of stateowned industrial enterprises used for analysis can be processed using relevant time series analysis models and methods. First, we pre-screen significant financial index data. This article uses the ARIMA model to predict the time series and compares it with the actual values, and from this, judges the impact of the COVID-19 on the financial status of state-owned industrial enterprises and my country after the outbreak of the COVID-19. The recovery of relevant financial conditions of state-owned industrial enterprises. In the process of selecting significant financial indicators, the current status of income and capital often reflects the development status of the enterprise, so this article will focus on the indicators related to the business status and capital stock of the enterprise. The accumulation of capital and the good growth of the company's business conditions are likely to have a greater impact on the company's short-term development status. In contrast, debt and liquidity will play a role in long-term corporate development, so the company's debt and liquidity situation is less likely to be affected by a major event. At the same time, the capitalization and scale of enterprises are the result of long-term development. The occurrence of short-term risk events is not expected to have a significant impact on these 
indicators, so no further consideration and in-depth exploration are required.

\subsection{Screening of Financial Indicators}

When dealing with problems, this paper draws on the research ideas of corporate financial distress models, and uses the logical and actual relationships between preprocessed financial indicators to calculate and screen financial indicators. The relevant financial indicators screened are as follows:

Table 1. Data of 20 financial indicators

\begin{tabular}{cccc}
\hline Indicator & Code & Indicator & Code \\
\hline Operating income growth rate & $\mathrm{n} 01$ & Total asset growth rate & $\mathrm{n} 06$ \\
operating profit & $\mathrm{n} 02$ & Inventory turnover & $\mathrm{n} 07$ \\
Assets and liabilities & $\mathrm{n} 03$ & Accounts Receivable Turnover Rate & $\mathrm{n} 08$ \\
Operating profit growth rate & $\mathrm{n} 04$ & Liquid assets turnover rate & $\mathrm{n} 09$ \\
Total profit growth rate & $\mathrm{n} 05$ & Operating profit margin & $\mathrm{n} 10$ \\
Turnover rate of total assets & $\mathrm{n} 11$ & Loss side & $\mathrm{n} 16$ \\
Equity ratio & $\mathrm{n} 12$ & Sales expense growth rate & $\mathrm{n} 17$ \\
Current assets ratio & $\mathrm{n} 13$ & Financial expense growth rate & $\mathrm{n} 18$ \\
Owner's equity ratio & $\mathrm{n} 14$ & Investment income growth rate & $\mathrm{n} 19$ \\
Debt-to-equity ratio & $\mathrm{n} 15$ & Management expense growth rate & $\mathrm{n} 20$ \\
\hline
\end{tabular}

According to these indicators, we can find that the financial indicators of state-owned industrial enterprises that have changed significantly during the COVID-19 are: total asset growth rate, financial expense growth rate, operating income growth rate, self-proclaimed debt ratio, owner's equity ratio, loss ratio, Operating profit growth rate, sales expense growth rate, and management expense growth rate. Selecting individual indicators among indicators helps simplify the research process of economic innovation.

At the same time, the correlation analysis of these 20 indicators is carried out, and the correlation coefficient table between each indicator is as follows:

Table 2. Correlation coefficient table

\begin{tabular}{|c|c|c|c|c|c|c|c|c|c|c|}
\hline Var & n01 & n02 & n03 & n04 & n05 & n06 & n07 & n08 & n09 & n10 \\
\hline n01 & 1.000 & & & & & & & & & \\
\hline n02 & 0.606 & 1.000 & & & & & & & & \\
\hline n03 & -0.412 & \begin{tabular}{|l|l|} 
\\
\end{tabular} & 1.000 & & & & & & & \\
\hline n04 & 0.342 & 0.212 & -0.346 & 1.000 & & & & & & \\
\hline n05 & 0.323 & 0.152 & -0.336 & 0.991 & 1.000 & & & & & \\
\hline n06 & 0.630 & -0.277 & -0.254 & 0.049 & 0.058 & 1.000 & & & & \\
\hline n07 & -0.242 & -0.187 & -0.296 & 0.244 & 0.243 & 0.512 & 1.000 & & & \\
\hline n08 & 0.014 & -0.162 & -0.265 & 0.386 & 0.393 & 0.062 & 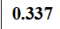 & 1.000 & & \\
\hline n09 & -0.259 & -0.221 & -0.292 & 0.252 & 0.252 & 0.529 & $\mid 0.998$ & 0.326 & 1.000 & \\
\hline n10 & 0.342 & 0.212 & -0.346 & 1.000 & 0.991 & 0.049 & 0.244 & 0.386 & 0.252 & 1.000 \\
\hline Var & n01 & n02 & n03 & n04 & n05 & n06 & n07 & n08 & n09 & n10 \\
\hline n11 & -0.041 & -0.229 & -0.214 & 0.385 & 0.388 & 0.074 & 0.304 & 0.986 & 0.298 & 0.385 \\
\hline n12 & -0.398 & -0.328 & 0.996 & -0.360 & -0.351 & -0.271 & -0.284 & -0.241 & -0.284 & -0.360 \\
\hline n13 & -0.596 & -0.540 & 0.927 & -0.253 & -0.232 & 0.004 & -0.217 & -0.245 & -0.196 & -0.253 \\
\hline n14 & 0.413 & 0.350 & -1.000 & 0.348 & 0.337 & 0.254 & 0.297 & 0.266 & 0.293 & 0.348 \\
\hline n15 & -0.398 & -0.328 & 0.996 & -0.360 & -0.351 & -0.271 & -0.284 & -0.241 & -0.284 & -0.360 \\
\hline n16 & -0.727 & -0.442 & 0.349 & -0.452 & -0.467 & 0.203 & 0.094 & 0.213 & 0.091 & -0.452 \\
\hline n17 & 0.322 & 0.291 & 0.103 & -0.230 & -0.233 & -0.391 & -0.670 & -0.246 & -0.686 & -0.230 \\
\hline n18 & -0.242 & -0.024 & -0.062 & -0.527 & -0.526 & 0.174 & 0.270 & -0.161 & 0.260 & -0.527 \\
\hline n19 & -0.509 & -0.427 & 0.146 & -0.389 & -0.352 & 0.349 & 0.227 & 0.151 & 0.216 & -0.389 \\
\hline $\mathrm{n} 20$ & 0.303 & 0.099 & 0.076 & -0.261 & -0.222 & -0.411 & -0.557 & -0.284 & -0.571 & -0.261 \\
\hline
\end{tabular}

\begin{tabular}{|l|c|c|c|c|c|c|c|c|c|c|}
\hline Var & $\mathrm{n} 01$ & $\mathrm{n} 02$ & $\mathrm{n} 03$ & $\mathrm{n} 04$ & $\mathrm{n} 05$ & $\mathrm{n} 06$ & $\mathrm{n} 07$ & $\mathrm{n} 08$ & $\mathrm{n} 09$ & $\mathrm{n} 10$ \\
\hline $\mathrm{n} 11$ & 1.000 & & & & & & & & & \\
\hline $\mathrm{n} 12$ & -0.189 & 1.000 & & & & & & & & \\
\hline $\mathrm{n} 13$ & -0.163 & 0.904 & 1.000 & & & & & & & \\
\hline $\mathrm{n} 14$ & 0.215 & -0.996 & -0.926 & 1.000 & & & & & & \\
\hline $\mathrm{n} 15$ & -0.189 & 1.000 & 0.904 & -0.996 & 1.000 & & & & & \\
\hline $\mathrm{n} 16$ & 0.281 & 0.376 & 0.394 & -0.349 & 0.376 & 1.000 & & & & \\
\hline $\mathrm{n} 17$ & -0.251 & 0.126 & -0.017 & -0.102 & 0.126 & -0.056 & 1.000 & & & \\
\hline $\mathrm{n} 18$ & -0.213 & -0.057 & -0.066 & 0.063 & -0.057 & 0.216 & 0.000 & 1.000 & & \\
\hline $\mathrm{n} 19$ & 0.203 & 0.192 & 0.244 & -0.144 & 0.192 & 0.535 & 0.016 & 0.321 & 1.000 & \\
\hline $\mathrm{n} 20$ & -0.346 & 0.068 & -0.027 & -0.075 & 0.068 & -0.328 & 0.545 & 0.114 & -0.060 & 1.000 \\
\hline
\end{tabular}

\subsection{ARIMA Analysis}

Here, this article mainly uses the ARIMA model to make time series related predictions and then compares with actual values. From this to judge the impact of the COVID-19 on the financial status of state-owned industrial enterprises.

When using the ARIMA model, this article found the most significant changes in the operating income growth rate in the pre-screening results of financial indicators, so this article uses the growth rate of operating income to establish an ARIMA model to observe the extent to which state-owned industrial enterprises are affected by the COVID-19 and the recovery of related financial conditions of state-owned industrial enterprises after the major public health incident.

Assuming that the time series after sub-differentiation can meet the ARIMA model's stability condition, the time series needs to be sub-differentiated, and the result after sub-differentiation is:

$$
y n_{t}=y(n-1)_{t}-y(n-2)
$$

The form of the constructed ARIMA model is:

$$
y n_{t}=\sum_{r=1}^{p} \phi y n_{t-i}+\varepsilon_{t}-\sum_{i=1}^{q} \theta_{i} \varepsilon_{t-i}
$$

Among them: $p, q$ is the undetermined coefficient of the model, $\varepsilon_{t}$ is the error, $\phi_{i}, \theta_{i}$ is the undetermined coefficient of the model, and $y n_{t}$ is the stationary time series.

Table 3. The actual value

\begin{tabular}{c|c|c|c|c|c|c|c}
\hline Time & $\mathbf{2 0 1 9 . 4}$ & $\mathbf{2 0 1 9 . 5}$ & $\mathbf{2 0 1 9 . 6}$ & $\mathbf{2 0 1 9 . 7}$ & $\mathbf{2 0 1 9 . 8}$ & $\mathbf{2 0 1 9 . 9}$ & $\mathbf{2 0 1 9 . 1 0}$ \\
\hline $\begin{array}{c}\text { Growth } \\
\text { rate }\end{array}$ & 4.2 & 4.2 & 4.9 & 5.8 & 8.3 & 7.1 & 7.4 \\
\hline Time & $\mathbf{2 0 1 9 . 1 1}$ & $\mathbf{2 0 1 9 . 1 2}$ & $\mathbf{2 0 2 0 . 2}$ & $\mathbf{2 0 2 0 . 3}$ & $\mathbf{2 0 2 0 . 4}$ & $\mathbf{2 0 2 0 . 5}$ & $\mathbf{2 0 2 0 . 6}$ \\
\hline $\begin{array}{c}\text { Growth } \\
\text { rate }\end{array}$ & 9.2 & 8 & -3.5 & -4.9 & -3.6 & -1.8 & -0.2 \\
\hline Time & $\mathbf{2 0 2 0 . 7}$ & $\mathbf{2 0 2 0 . 8}$ & $\mathbf{2 0 2 0 . 9}$ & $\mathbf{2 0 2 0 . 1 0}$ & $\mathbf{2 0 2 0 . 1 1}$ & $\mathbf{2 0 2 0 . 1 2}$ & $\mathbf{2 0 2 1 . 2}$ \\
\hline $\begin{array}{c}\text { Growth } \\
\text { rate }\end{array}$ & -1.7 & -0.6 & 1.5 & 2.4 & 3 & 3.5 & 9.0 \\
\hline
\end{tabular}

This article adopts the idea and method of the ARIMA model to deal with the main process as follows, after screening the relevant financial indicators, the time series are observed and the difference operation is performed, and then the original data and the original data after the difference are tested for stationarity, and the ARIMA 
model is used to predict and fit Then carry out residual analysis:

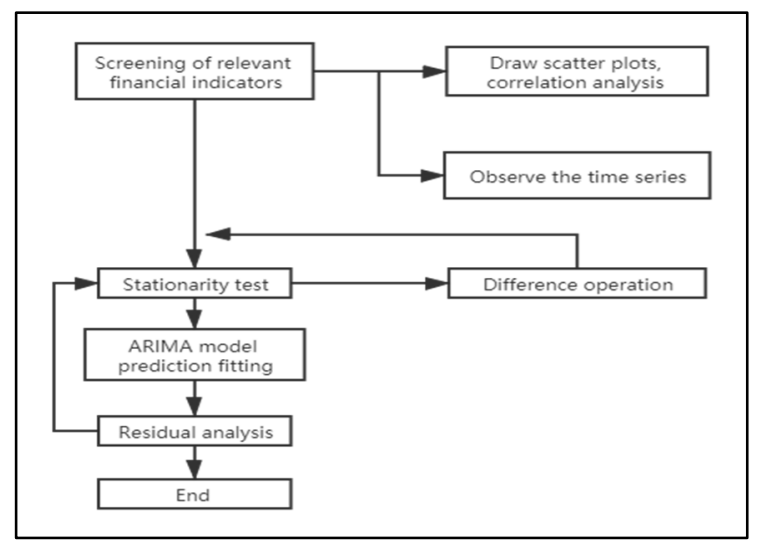

Figure 2. ARIMA analysis steps

The main idea of adopting the ARIMA model is to first select the most relevant indicators from 20 related composite financial indicators to analyze the impact of the COVID-19 on the development of state-owned industrial enterprises, and then observe the time series to test the stability of the data used. Perform multiple differential operations at the same time.Using the time dimension to study the changes of the state-owned economy is an innovation path in the state-owned economy related research, and based on this, the realization of the innovation of the state-owned economy is realized.

This paper uses MATLAB software to perform ACF and PACF tests after the difference between the operating income growth rate and the operating income growth rate. The test results are as follows. The test results indicate that the operating income growth rate is a data indicator that is stable enough for further prediction and analysis:

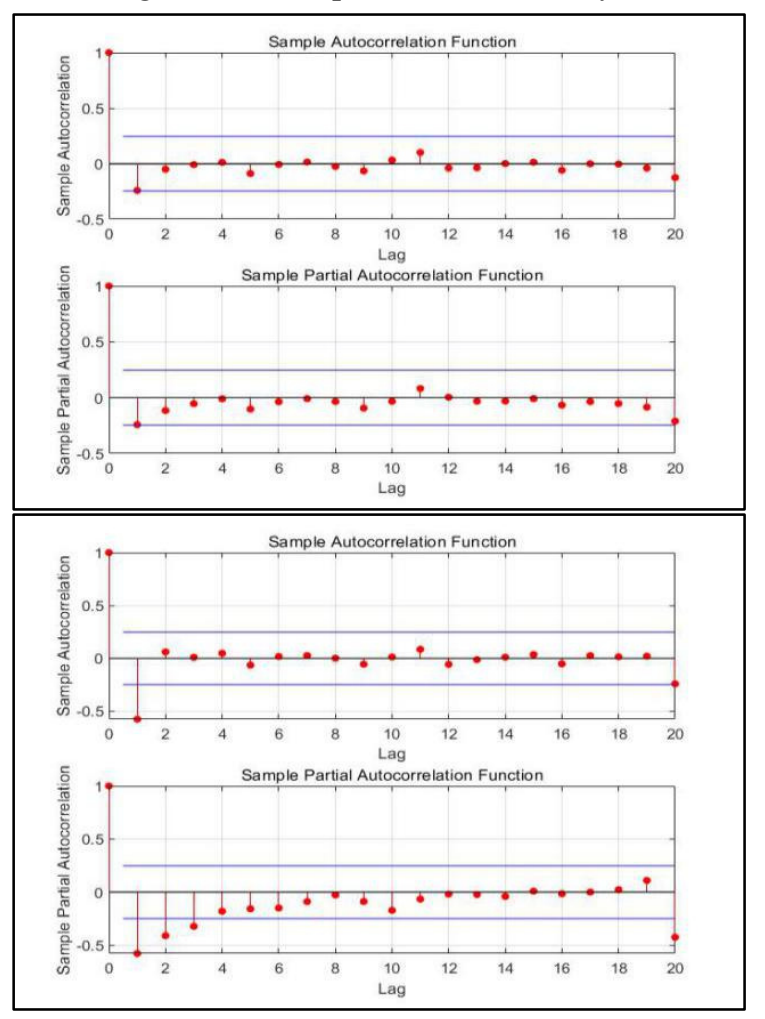

Figure 3. ACF and PACF test chart
Using the ARIMA model to predict and fit, and then use the residual analysis method to determine the difference between the actual value of the revenue growth rate of the business graphics industry and the predicted value. This explains the changes in the business and production conditions of state-owned industrial enterprises under the influence of the new crown pneumonia.

\subsection{Statistical measurement of COVID-19 incidents on the development of China's state- owned industrial enterprises}

Considering special fluctuations in the research process will be of reference value for the research on the innovation route of the state-owned economy. When faced with many risks, how to implement adjustment strategies and programs is an important source of economic innovation.

Based on the data on the growth rate of operating income from February 2015 to December 2019, the ARIMA model is used to predict data under normal conditions after the outbreak (from February 2020 to June 2020), and includes the recovery period after the epidemic (July 2020 to January 2021) Under normal circumstances, the growth rate data is compared with actual data, that is, residual analysis, to judge the impact of the COVID-19 on state-owned industrial enterprises and their business conditions after the epidemic.

By defining the degree of impact and the degree of recovery to specifically quantify the impact of the COVID-19 on the development of state-owned industrial enterprises, it can not only explain the impact of the epidemic, but also conduct theoretical analysis on the recovery of state-owned industrial enterprises.

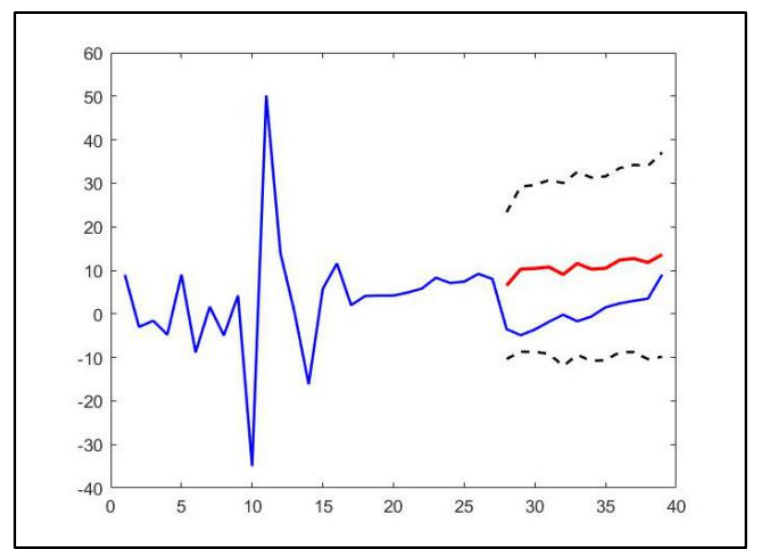

Figure 4. Predicted value and actual value comparison

The operating results of the ARIMA model are shown in Figure 4. The abscissa is time and the ordinate is the growth rate of operating income; the yellow curve is the predicted value of the growth rate of operating income under normal circumstances, and the blue curve is the growth rate of operating income under the influence of the epidemic.

The comparison of actual and predicted data will have a certain reference value for the realization of economic innovation. 
Table 4. Forecast of the growth rate of operating income

\begin{tabular}{c|c|c|c|c|c|c|c}
\hline Time & $\mathbf{2 0 1 9 . 4}$ & $\mathbf{2 0 1 9 . 5}$ & $\mathbf{2 0 1 9 . 6}$ & $\mathbf{2 0 1 9 . 7}$ & $\mathbf{2 0 1 9 . 8}$ & $\mathbf{2 0 1 9 . 9}$ & $\mathbf{2 0 1 9 . 1 0}$ \\
\hline Growth rate & 4.2 & 4.2 & 4.9 & 5.8 & 8.3 & 7.1 & 7.4 \\
\hline Time & $\mathbf{2 0 1 9 . 1 1}$ & $\mathbf{2 0 1 9 . 1 2}$ & $\mathbf{2 0 2 0 . 2}$ & $\mathbf{2 0 2 0 . 3}$ & $\mathbf{2 0 2 0 . 4}$ & $\mathbf{2 0 2 0 . 5}$ & $\mathbf{2 0 2 0 . 6}$ \\
\hline Growth rate & 9.2 & 8 & 6.50 & 10.28 & 10.43 & 10.77 & 9.04 \\
\hline Time & $\mathbf{2 0 2 0 . 7}$ & $\mathbf{2 0 2 0 . 8}$ & $\mathbf{2 0 2 0 . 9}$ & $\mathbf{2 0 2 0 . 1 0}$ & $\mathbf{2 0 2 0 . 1 1}$ & $\mathbf{2 0 2 0 . 1 2}$ & $\mathbf{2 0 2 1 . 2}$ \\
\hline Growth rate & 11.58 & 10.27 & 10.47 & 12.36 & 12.72 & 11.79 & 13.61 \\
\hline
\end{tabular}

The impact of the epidemic on the operations of stateowned industrial enterprises and the degree of recovery after the epidemic are measured by the following indicators:

Influence level:

$$
\Delta x_{i}=x_{i}-x_{i f}
$$

Recovery degree:

$$
\Delta h_{i}=h_{i}-h_{i f}
$$

among them, $h_{i f}$ and $x_{i f}$ is the predicted value of the operating income growth rate in the $i$ period,

$h_{i}$ and $x_{i}$ is the actual value of the operating income growth rate in the $i$ period,

And stipulate the average degree of recovery:

$$
\Delta h=\frac{\sum_{i=1}^{n} \Delta h_{i}}{n}
$$

Average degree of impact:

$$
\Delta x=\frac{\sum_{i=1}^{n} \Delta x_{i}}{n}
$$

Table 5. The degree of recovery and influence level

\begin{tabular}{|c|c|c|c|c|c|c|c|c|}
\hline Time & $\begin{array}{c}\text { Average } \\
\text { influence }\end{array}$ & $\mathbf{2 0 2 0 . 2}$ & $\mathbf{2 0 2 0 . 3}$ & $\mathbf{2 0 2 0 . 4}$ & $\mathbf{2 0 2 0 . 5}$ & $\mathbf{2 0 2 0 . 6}$ \\
\hline $\begin{array}{c}\text { Influence } \\
\text { level }\end{array}$ & -12.20 & -10.00 & -15.18 & \multicolumn{2}{|c|}{-14.03} & -12.57 & -9.24 \\
\hline Time & $\begin{array}{c}\text { Average } \\
\text { recovery }\end{array}$ & $\mathbf{2 0 2 0 . 7}$ & $\mathbf{2 0 2 0 . 8}$ & $\mathbf{2 0 2 0 . 9}$ & $\mathbf{2 0 2 0 . 1 0}$ & $\mathbf{2 0 2 0 . 1 1}$ & $\mathbf{2 0 2 0 . 1 2}$ & $\mathbf{2 0 2 1 . 2}$ \\
\hline $\begin{array}{c}\text { Degree of } \\
\text { recovery }\end{array}$ & -9.39 & -13.28 & -10.87 & -8.97 & -9.96 & -9.72 & -8.29 & -4.61 \\
\hline
\end{tabular}

Through quantitative analysis, it was found that the degree of influence and recovery of state-owned industrial enterprises gradually increased as the degree of the epidemic worsened. The development and operating conditions of state-owned industrial enterprises were both affected during the outbreak of the epidemic and during the second outbreak. A significant negative impact. And with the passage of time, the situation of the epidemic has gradually improved, and the operation and development of state-owned industrial enterprises have gradually improved with the recovery of the economy and the standardization of production order. After the initial outbreak of the epidemic, state-owned industrial enterprises were most negatively affected in March 2020, and then gradually showed a weakening trend. They were the most negatively affected during the second outbreak of the epidemic in July 2020, and then gradually recovered. The recovery of the economy shows that economic innovation needs to be realized from the supply side and demand measurement. The innovation of the state-owned economy must consider its special development status to achieve better overall planning and development.

\subsection{Robustness test}

\subsubsection{White noise test of first-order difference}

This article uses the data after the first-order difference of the original operating income growth rate to perform a white noise test, that is, a hypothesis test on the randomness of the data sequence, and after the $p$ value is obtained, it is used to determine whether the data is white noise data. When the $\mathrm{p}$ value When it is greater than 0.5 , the time series data is considered to be white noise data, and the predictive analysis result is significant.

Table 6. White noise test of first-order difference

\begin{tabular}{ccc}
\hline Delay order & Chi-square statistics & P-value \\
\hline 6 & 2.470401 & 0.871765 \\
12 & 8.371864 & 0.755437 \\
18 & 12.18266 & 0.837665 \\
\hline
\end{tabular}

\subsubsection{Simple exponential smoothing method for significance test.}

Through the robustness test of the simple exponential smoothing method, it is found that the significant time changes, the degree of influence and recovery in the model, and the sign coefficients involved are completely consistent with the ARIMA model. In terms of significance level, predictive analysis is significant at the $1 \%$ significance level.

\section{Conclusions and suggestions}

\subsection{Conclusions}

(1) During the first and second outbreaks of the COVID19 , its path of influence is to affect the supply and demand sides of the production and operation of state-owned industrial enterprises, and then affect the financial status of state-owned industrial enterprises.

(2) After the first outbreak of the epidemic, stateowned industrial enterprises were most negatively affected in March 2020, and then gradually showed a trend of weakening. They were most negatively affected during the second outbreak of the epidemic in July 2020, and then 
gradually recovered. Its operation and development conditions have gradually improved with the recovery of the economy and the standardization of production order.

(3) After the second outbreak of the epidemic, although the level of impact on state-owned industrial enterprises was lower than the highest level of impact compared to the first outbreak, the level of impact was still high, reaching -13.28 .

\subsection{Suggestions}

(1) In the daily operation and management of state-owned industrial enterprises, the awareness of emergency management and risk prevention should be strengthened to prevent serious impacts on the business status of the enterprise when a major public health incident similar to the COVID-19 occurs. Specific measures can include: strengthening the supply chain management of the industrial chain, sorting out the supply-side and demandside conditions of enterprises in various industries; technology to reduce enterprise costs, encouraging enterprises to use information and technological means to promote production transformation and management model upgrades, and reduce raw materials and Human resource consumption, to achieve cost reduction and efficiency enhancement.

(2) For state-owned industrial enterprises, in order to better their business operation and development level, they should pay special attention to the impact of the second outbreak of the epidemic after facing similar major public health incidents, and strengthen the supply chain and industrial chain cooperation. To speed up the turnover of goods and control the cost and debt situation, in order to have good and perfect emergency management measures when similar major public health incidents occur again.

(3) For state-owned enterprises, they should make good use of the advantages of large platforms and abundant resources to do a good job in development and upgrading. Especially in the industrial field, we should focus on resource integration, improve turnover efficiency, and broaden profit margins to help the transformation and upgrading of my country's industrial intelligence and digitalization, which also will be helpful to the innovative development of economy.

\section{References}

1. Li S., (2020) Analysis on the Realization Path of the Expected Development of National Enterprises in the New Era-Based on the Research of Construction Industry, Academic Research, 03,88-94

2. Liu S., (2021) The impact of the new crown pneumonia epidemic on China's regional economy,Geographical Research, 40(02), 310-325.

3. Rendon, Andres F.V., Volschan, Isabela M., Pereira, Manoella N. etc., (2021) Marginalization, Vulnerability and Economic Dynamics in COVID-19, International Journal of Cardiovascular Science, 34, 319-323.
4. Chen C., Zhao D., (2020) Analysis of the deduction and prevention and control of the new crown pneumonia epidemic crisis from the perspective of social economy, China Safety Science Journal, 30(12), 24-29.

5. Yu Y., Zhao C., Zhang S., (2020) Research on the Strategic Adjustment of China's Economic Objectives Under the Impact of the New Coronary Pneumonia Epidemic, Economics and Management Research, 41(11), 3-18.

6. Du J., Zhao W., (2020) Analysis of the effect of China's financial policies on improving social and economic resilience during the epidemic, Hebei Academic Journal, 40(06), 125-130.

7. Fan H., (2020) Post-epidemic era and high-quality economic and social development, Shandong Social Science, 09,62.

8. Fang D., (2020) Research on Measurement of Industrial Economic Efficiency and Its Influencing Factors in the Yangtze River Economic Zone, Theory Monthly 11, 89-96.

9. Ali, Syed M., Paul, Sanjoy K., Chowdhury, P.,(2021) Modelling of supply chain disruption analytics using an integrated approach: An emerging economy example, EXPERT SYSTEMS WITH APPLICATIONS, 173.

10. Liu S., Jia X., Dang J., (2020) Research on the Measurement and Influencing Factors of China's Industrial Green Total Factor Productivity, Ecological Economy, 36(11), 46-53.

11. Yang Z., Li X., Liu H., Liu Y., (2017) Research on the Measurement and Impact of my country's Industrial Technology Progress under the New Normal__An Empirical Analysis Based on Inter-provincial Panel Data, Journal of Jiangxi Normal University (Natural Science Edition), 41(02), 189-192.

12. Lieder, Michael, Rashid, Amir, (2016) Towards circular economy implementation: a comprehensive review in context of manufacturing industry, JOURNAL OF CLEANER PRODUCTION, 115, 3651.

13. Wang Y., Lin H., Wang J., (2013) Industrial Structure Conversion Ability in Central China: Measurement, Convergence and Influencing Factors, Journal of Shanxi University of Finance and Economic, 35(06), 60-69.

14. Gu Z., (2014) Research on China's Industrial Efficiency Measurement and Influencing Factors from the Environmental Perspective, Statistics and Decision, 01, 128-133.

15. Luo M., Fan R., Zhang Y., (2020) Analysis of the Influence Mechanism of Multi-agent Behaviors on Industrial Energy Efficiency-The Perspective of Heterogeneous Subject Research, Technological Economy and Management Research, 08, 72-78. 